\title{
A 'greener' one-pot synthesis of monoterpene-functionalised lactide oligomers
}

Dara M. O'Brien, ${ }^{1+}$ Rachel L. Atkinson,,${ }^{1+}$ Robert Cavanagh, ${ }^{2}$ Ana A. C. Pacheco, ${ }^{1}$ Ryan Larder, ${ }^{1}$ Kristoffer Kortsen, ${ }^{1}$ Eduards Krumins, ${ }^{1}$ Alice J. Haddleton, ${ }^{1}$ Cameron Alexander, ${ }^{2}$ Robert A. Stockman, ${ }^{1}$ Steven M. Howdle ${ }^{1}$ and Vincenzo Taresco ${ }^{1 *}$

\footnotetext{
${ }^{1}$ University of Nottingham, School of Chemistry, University Park, NG7 2RD, UK

${ }^{2}$ University of Nottingham, School of Pharmacy, University Park, NG7 2RD, UK

${ }^{\dagger}$ These authors contributed equally.
}

*Corresponding author: vincenzo.taresco@nottingham.ac.uk

\section{Highlights}

- Improved sustainability of the Ring Opening Polymerisation (ROP) of lactide (LA) by employing renewable terpene-based initiators in combination with the biorenewable solvent 2-Methyl Tetrahydrofuran (2-MeTHF) was achieved.

- A small library of terpene-alcohols was used as initiators in the generation of PDLLA oligomers

- These oligomers were found to self-assemble in water to form well-defined nanoparticles (NPs) without the use of additional stabilisers or co-monomers.

- The nanoparticles formed were found to be biocompatible when tested on lung, intestinal and skin cells, hinting at the possibility of a broad range of applications for these novel materials.

\section{Keywords}

Ring Opening Polymerisation (ROP), Nanoparticles (NPs), surfactants, sustainability, green synthesis, terpene, renewable polymers

\begin{abstract}
In this work we aimed to achieve a totally sustainable Ring Opening Polymerisation (ROP) process, by harmonising the use of naturally occurring or derivable initiators and the green solvent 2Methyltetrahydrofuran (2-MeTHF). First, a library of novel monoterpene-alcohols and existing terpenoids was used to provide renewably sourced initiators for a metal-free ROP synthetic step. A number of these initiators are derived from waste materials, further improving their sustainability. Secondly, we selected lactide (LA) as a monomer, because not only is it derived from biomass, but its resultant polymers are biocompatible and biodegradable. Interestingly, these new polymers selfassembled in water producing well defined, biocompatible nanoparticles (NPs) via direct nanoprecipitation without the use of additional stabilisers. We have highlighted a novel and promising (ROP) approach to produce biodegradable, amphiphilic ester-based macromolecules, based on lactide and terpenes (as initiators) in a green solvent, 2-MeTHF thus reducing solvent toxicity in an efficient, simple and sustainable new synthesis. The monoterpenes may provide a highly functionalisable and bio-renewable toolbox for a new generation of ROP initiators.
\end{abstract}




\section{Introduction}

In the last century, the reliance of the global population on polymer-based materials increased twentyfold.[1] In 2015, synthetic polymer production worldwide reached 300 million tonnes, [2] and with the global population estimated to pass ten billion by 2050,[3] this reliance on polymer materials brings a variety of problems around sustainability,[4] environmental[5] and economic[1] issues. Despite a growing demand for renewable plastic material, sustainable polymers still only constitute less than $10 \%$ of the total commercial plastics market.[2] With crude oil and gas feedstocks expected to be entirely depleted within the next century,[6] this alone demands that polymer production finds new, renewable feedstocks.

Terpenes are one source of hydrocarbon rich molecular biomass that have generated much interest. This diverse family of naturally occurring compounds are abundant in nature and do not compete directly with food sources,[7] making them attractive feedstocks for renewable polymers.[8]

'Monoterpenes', comprised of two isoprene units, with the general formula $\mathrm{C}_{10} \mathrm{H}_{16}$, are the most common.[7] Turpentine, the volatile fraction isolated from pine resin, is the primary source of a variety of terpenes and is produced on a scale of about 330,000 tonnes per year. [7,9] Its composition is dependent on the age and species of the tree, amongst other factors, but its major components are $\alpha$-pinene and $\beta$-pinene, along with small amounts of other monoterpenes such as limonene. Other monoterpenes can be easily accessed from these compounds, as can their oxygenated 'terpenoid' derivatives including menthol, carvone and other cyclic terpene alcohols.[10]

Terpenes and terpenoids have shown huge potential for polymerisation after functionalisation.[11] In particular, in the last few years there has been interest in the chemical exploitation of these naturally occurring materials to produce polymers with tunable properties.[7] The radical polymerisation of a variety of terpene-based (meth)acrylates has been recently reported,[12] as has the polymerisation of functionalised terpenes leading to alternating co-polymerisation of carbon dioxide and limonene oxide.[13] Other research has screened the most atom-efficient and sustainable pathways, among the widely reported and less conventional methods, for the synthesis of a range of terpenoid-based (meth)acrylates with the help of the recently developed CHEM21 green metrics toolkit.[14]

Ring opening polymerisation (ROP) methods have also proved to be key in the polymerisation of terpenes.[15] For instance, Zhang et al. showed that the seven-membered lactone menthide could be accessed from menthone, before undergoing ROP with a zinc-alkoxide catalyst to yield aliphatic polyesters.[16,17] Quilter et al. reported a high-yielding 4-step process for converting $\beta$-pinene into a biorenewable replacement of $\varepsilon$-caprolactone, as well as the homo- and co-polymerisation of the novel cyclic monomer.[18] Additionally, Winnacker et al. developed an alternative synthetic bio-pathway for the production of polyamides, produced via ROP of a lactam-based $\beta$-pinene, which showed excellent thermal properties. $[19,20]$

To our knowledge, there is only one example of mono- and di-terpenoids having been previously investigated as possible ring opening initiators.[21,22] In this instance, Zhao et al. used a library of terpene alcohols (menthol, retinol, cholesterol, and betulin) as initiators for anionic ROP of ethylene oxide, catalysed by the phosphazene base, $t$ - $\mathrm{BuP}_{4}$, with the intent of producing a series of polymers with tunable properties.[21]

In this paper we aim to expand the number of terpene-based ROP initiators. In an effort to minimise synthetic steps, waste and the overall energy involved in the synthesis, the designated library of monoterpene- $\mathrm{OH}$ s was made up of a variety of molecules that are either commercially available, or 
were already present in our in-house library, as intermediates in the production of (meth)acrylicderivatives. $[23,24]$

One of the most successful bioderived polymers is polylactide (PDLLA).[25-27] It has received significant commercial attention as it has the potential to replace polyolefins and other petrochemicalderived polymers.[7] In 2014, this polymer accounted for one of the three main products by volume of the renewable polymer industry.[28] PDLLA is a particularly attractive sustainable polymeric material because not only is it derived from biomass, but it is also biocompatible and biodegradable, breaking down to form lactic acid.[29] This makes it suitable for biomedical applications such as drug or vaccine delivery. PDLLA therefore offers an example of a useful polymer that can be considered safe and devoid of any major toxicity.[29]

Owing to its polarity and high miscibility with a variety of organic compounds, dichloromethane (DCM) has been commonly employed as a solvent for the synthesis of PDLLA via the ROP of lactide (LA). [3032] However, DCM is known to be carcinogenic to humans according to the World Health Organization IARC evaluations, and contributes to ozone depletion.[33] As a result, the European regulation concerning the 'Registration, Evaluation, Authorisation and Restriction of Chemicals' (REACH) has introduced specific restrictions for DCM and its use.[33] Alternatively, 2-Methyltetrahydrofuran (2MeTHF) is a successful neoteric bio-based solvent replacement for DCM, Toluene and THF. In fact, it has been adopted in a wide range of chemical processes.[34] 2-MeTHF is a volatile cyclic ether that can be derived from the chemo-catalytic treatment of biomass.[35] It is appealing as a solvent for a variety of organocatalysed reactions and biotransformations because of its boiling point, low miscibility with water and higher stability compared to THF.[35] A further distinct advantage of the use of 2-MeTHF in place of DCM, is that it is known to be 'inversely soluble' in water with increase in temperature. This is of particular advantage for the ROP reactions in this paper, which must be performed in the absence of water.[36]

Our aim is to expand the number of renewable and further-functionalisable initiators for ROP and for the first time to develop a process using a naturally occurring monomer, initiator, catalyst and solvent, in a fully green and sustainable process. The catalyst is 1,8-Diazabicyclo[5.4.0]undec-7-ene (DBU), a naturally occurring, non-nucleophilic amidine base[30-32] which has mild activity to minimise side reactions and preserve key functionalities both on the headgroups, backbone and end-group moieties.[30,37]

A key target is to demonstrate the crucial importance of the retention of the "terpenoid double bond" motif along the headgroups of the bio-hybrid polyesters, to provide a versatile docking-point for the production of highly functionalised, degradable polymeric platforms; for example in future work via thiol-ene addition chemistry.[38] Functionalisation of the terpene alkene motif in this way has been recently demonstrated by Weems et al. in the production of resins using thiols for 'click' reactions, via photopolymerisation.[39] 


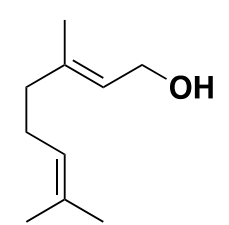

geraniol

(ger)

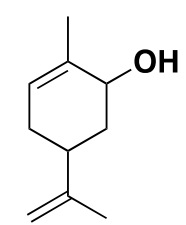

carveol

(car)<smiles>CC1=CCC(C(C)CO)CC1</smiles>

limonene-OH (lim-OH)<smiles>CC1=CCC(C(C)(C)O)C[C@H]1O</smiles>

trans-sobrerol

$t$-sob

Scheme 1. The structures of the terpene-OH initiators. Geraniol (ger) and carveol (car) are commercially available natural products, while limonene- $\mathrm{OH}(\mathrm{lim}-\mathrm{OH})$ and trans-sobrerol $(t$-sob) are known compounds from our in-house terpene library.[23]'[24]

\section{Experimental Section}

\section{Materials}

Commercially available chemical reagents were purchased from Merck, Sigma Aldrich or Fischer Scientific UK and used as received unless otherwise stated. Solvents were purchased from Fischer Scientific UK and used without further purification unless otherwise stated. Water was deionised before use. Brine is a saturated aqueous solution of sodium chloride. Solvent evaporation was performed using a rotary evaporator under reduced pressure.

\section{General Methods and Instrumentation}

Nuclear magnetic resonance spectroscopy: Conversion of each reaction and degree of polymerisation were determined using ${ }^{1} \mathrm{H}$ nuclear magnetic resonance spectroscopy. Samples were dissolved in $\mathrm{CDCl}_{3}$ and analysed using a Bruker DPX $400 \mathrm{MHz}$ spectrometer operating at $400 \mathrm{MHz}\left({ }^{1} \mathrm{H}\right)$ and $100 \mathrm{MHz}\left({ }^{13} \mathrm{C}\right)$. Chemical shifts were assigned in parts per million (ppm). All spectra were obtained at ambient temperature $\left(22^{\circ} \mathrm{C} \pm 1\right)$. MestReNova 6.0.2 copyright 2009 (Mestrelab Research S. L.) was used for analysing the spectra.

Fourier-Transform Infra-Red Spectroscopy: Spectra were recorded with an Attenuated Total Reflection Cary 630 FTIR spectrophotometer (Agilent Technologies, Santa Clara, CA). 32 interferograms were recorded for each spectrum, with a resolution of $4 \mathrm{~cm}^{-1}$, in the range 4000-650 $\mathrm{cm}^{-1}$. IR spectra were analysed by SpectraGryph1.2 software.

Size Exclusion Chromatography (SEC) was performed in THF (HPLC grade, Fisher Scientific) as the eluent at room temperature using two Agilent PL-gel mixed-E columns in series with a flow rate of $1 \mathrm{~mL} \mathrm{~min}{ }^{-1}$. A differential refractometer (DRI), were used for sample detection. The system was calibrated using polylactide standards.

Differential Scanning Calorimetry (DSC) was used to determine the glass transition temperature $\left(T_{\mathrm{g}}\right)$ of the polymers produced. The analysis was performed on a TA-Q2000 (TA instruments), which was calibrated with an indium standard under $\mathrm{N}_{2}$ flow. The sample (1-3 $\mathrm{mg}$ ) was weighed into a T-zero sample pan (TA instruments) with a reference T-zero pan remaining empty. Both pans were heated at a rate of $10{ }^{\circ} \mathrm{C} \mathrm{min}-1$, from $-90{ }^{\circ} \mathrm{C}$ to $120{ }^{\circ} \mathrm{C}$ for all samples. To remove any thermal history of the individual samples two heating cycles were recorded with the $T_{g}$ being measured from the second cycle.

Dynamic mechanical analysis (DMA) was used to determine the $T_{g}$ of the polymers. Measurements were performed on a Triton Technologies DMA (now Mettler Toledo DMA1) using the powder pocket 
accessory. The sample ( $40 \mathrm{mg} \pm 5 \mathrm{mg}$ ) was weighed into a powder pocket. Samples were measured at 1 and $10 \mathrm{~Hz}$ in single cantilever bending geometry between $-50-100{ }^{\circ} \mathrm{C}$ depending on the region of interest. The value of the $T_{\mathrm{g}}$ was taken as the peak of the tan delta $(\tan \delta)$ curve.

Water Contact Angle (WCA) values were recorded at at $25{ }^{\circ} \mathrm{C}$ by means of a KSV Cam 200 (KSV InstrumentsLtd., Helsinki, Finland). Samples were prepared by solvent casting of polymer in acetone solutions, at $5 \mathrm{mg} / \mathrm{mL}$, on cover slips. Polymer-coated slides were mounted horizontally on the stand of the instrument. A small drop of distilled water was dispensed by a syringe with a flattened tip needle onto the polymer film. Each droplet was allowed to settle and interact for $5 \mathrm{sec}$. The tangent line was recorded using a camera and both shape and contact angle were analysed. Three measurements were repeated for each sample.

Dynamic Light Scattering (DLS) and Z-potential: Particle size analyses were performed by DLS utilizing a Zetasizer Nano spectrometer (Malvern Instruments Ltd) equipped with a $633 \mathrm{~nm}$ laser at a fixed angle of $173^{\circ}$. The same instrument was used to measure the Z-potential of the produced NPs. All experiments were performed in triplicate on the same sample.

\section{'Greener' procedure for DBU-catalysed terpene-initiated ROP of Lactide in 2-MeTHF}

The desired amount of LA and initiators (car, ger, lim and $t$-sob) were weighed into a vial (pre-dried in an oven at $100{ }^{\circ} \mathrm{C}$ overnight). The [M]:[I] was kept fixed at 10:1 ratio. In case of $t$-sob-LA $10,0.98 \mathrm{mmol}$ $t$-sob and $9.8 \mathrm{mmol}$ of LA). Subsequently, 2-MeTHF ( $7 \mathrm{~mL}$ ) was added and the mixture was allowed to fully dissolve at $60^{\circ} \mathrm{C}$ (according to the initiators adopted) and the vial was capped. DBU was added at $1.5 \% \mathrm{~mol} / \mathrm{mol}$ (compared to the monomer) to initiate the ROP reaction at $60^{\circ} \mathrm{C}$. After 15 minutes of reaction, the process was stopped by adding the reaction mixture into cold heptane $(20-30 \mathrm{~mL})$. The same procedure was exploited to produce polymers with different $[\mathrm{M}] /[\mathrm{l}]$ ratios by either altering the monomer/initiator feed-stock ratio or using a preformed oligomer and further chain extension. The polymer was purified via two further precipitation steps (heptane was decanted and replaced with diethyl ether, the sample was then left in the freezer for 2 hour before decanting the organic solvent) and dried in a vacuum oven to obtain the final macromonomers (conversion of monomer in polymer circa $70 \%$ to full). Ger-LA 10 : conversion monomer in oligomer circa $70 \%$. ${ }^{1} \mathrm{H}$ NMR (400 $\mathrm{MHz}, \mathrm{CDCl} 3) \delta \mathrm{H}=5.19-5.13(\mathrm{~m}, 8 \mathrm{H}), 4.69-4.58(\mathrm{~m}, 1 \mathrm{H}), 4.39-4.29(\mathrm{~m}, 1 \mathrm{H}), 2.68(\mathrm{br} \mathrm{s}, 1 \mathrm{H}), 2.09-1.98(\mathrm{~m}$, $3 \mathrm{H}), 1.75-1.67(\mathrm{~m}, 6 \mathrm{H}), 1.59-1.55(\mathrm{~m}, 24 \mathrm{H}), 1.55-1.54(\mathrm{~m}, 3 \mathrm{H}), 1.50-1.46(\mathrm{~m}, 3 \mathrm{H})$. Calculated $\mathrm{M}_{\mathrm{n}}$ from NMR: $1150 \mathrm{Da}, \mathrm{M}_{\mathrm{n}}(\mathrm{GPC}) 1330 \mathrm{Da}$ and $Ð$ 1.2. To further prove the robustness of the reaction, DP 20 and 40 were also targeted. For these polymers the following results were observed: (DP 20) $M_{n}(G P C)$ $2200 \mathrm{Da}$ and $Ð 1.3$ and (targeted DP 40, observed DP of 35 units) $5000 \mathrm{Da} \oplus$ 1.3. However, due to our interest in investigating the behaviour of short oligomers as surfactant, only DP 10 and 20 have been taken into consideration.

\section{'Traditional' procedure for DBU-catalysed, terpene-initiated ROP of Lactide in DCM}

The desired amount of LA and initiator (ger) were weighed into a vial (pre-dried in an oven at $100{ }^{\circ} \mathrm{C}$ overnight). The [M]:[I] was kept fixed at 10:1 ratio. In case of ger- $\mathrm{LA}_{10}, 0.98 \mathrm{mmol} t$-sob and $9.8 \mathrm{mmol}$ of $L A)$. Subsequently, DCM was added $(7 \mathrm{~mL})$ and the mixture was allowed to fully dissolve. DBU was added at $1.5 \% \mathrm{~mol} / \mathrm{mol}$ (compared to the monomer) to initiate the ROP reaction at room temperature. After 15 minutes of reaction, the process was stopped by adding the reaction mixture into cold heptane $(20-30 \mathrm{~mL})$. The polymer was purified via two further precipitation steps (heptane was decanted and replaced with diethyl ether, the sample was then left in the freezer for 2 hour before decanting the organic solvent) and dried in a vacuum oven to obtain the final macromonomers (conversion of monomer in polymer circa $80 \%) .{ }^{1} \mathrm{H}$ NMR $(400 \mathrm{MHz}, \mathrm{CDCl} 3) \delta \mathrm{H}=5.19-5.13(\mathrm{~m}, 8 \mathrm{H}), 4.69-$ 4.58(m, $1 \mathrm{H}), 4.39-4.29(\mathrm{~m}, 1 \mathrm{H}), 2.68(\mathrm{br} \mathrm{s}, 1 \mathrm{H}), 2.09-1.98(\mathrm{~m}, 3 \mathrm{H}), 1.75-1.67(\mathrm{~m}, 6 \mathrm{H}), 1.59-1.55(\mathrm{~m}$, $24 \mathrm{H}), 1.55-1.54(\mathrm{~m}, 3 \mathrm{H}), 1.50-1.46(\mathrm{~m}, 3 \mathrm{H})$. Calculated $\mathrm{M}_{\mathrm{n}}$ from NMR: $1300 \mathrm{Da}, \mathrm{M}_{\mathrm{n}}(\mathrm{GPC}) 1650 \mathrm{Da}$ and $\oplus 1.2$. 


\section{Nanoparticle preparation and stability assay}

The polymeric nanoparticles (NPs) were formed via the nanoprecipitation method. More precisely, 1 $\mathrm{mL}$ of acetone solution containing $10 \mathrm{mg}$ of polymer was added to $10 \mathrm{~mL}$ of HPLC filtered water under constant stirring $(550 \mathrm{rpm})$. The water/acetone uncapped solutions were gently stirred over-night in order to facilitate acetone evaporation. Particle size analyses was then determined using DLS as described. Stability tests were performed by diluting the NP suspensions with PBS and monitoring the variations in sizes via DLS in a period of $48 \mathrm{~h}$.

\section{Critical Aggregation Concentration (CAC) calculation}

The Critical Aggregation Concentration (CAC) was calculated using a Zetasizer Nano ZS as described in Malvern application note AN101104 (http://www.malvern.com/en/support/resourcecenter/application notes/AN101104SurfactantMicelleCharacterization.aspx). A constant attenuator was selected and the count rate in kcps of the scattered light was monitored for a range of diluted NP suspensions $(1000-2.00 \mu \mathrm{g} / \mathrm{mL})$. The intensity increases linearly with concentration above the CAC, while below the CAC the count rates reach a plateau. The CAC was then calculated by intersecting the two lines.[30]

\section{Cell culture}

Caco-2 human adenocarcinomic colon epithelial cells, A549 human adenocarcinomic alveolar epithelial cells and A431 human epidermoid carcinoma cells were obtained from the American Type Culture Collection (ATCC; Manassas, Virginia) and used at passages 30-35, 20-25 and 25-30, respectively. All cells were cultured in DMEM (Sigma-Aldrich) supplemented with $10 \%(\mathrm{v} / \mathrm{v})$ FBS (Sigma-Aldrich) and $2 \mathrm{mM} \mathrm{L-glutamine} \mathrm{(Sigma-Aldrich),} \mathrm{and} \mathrm{at} 37^{\circ} \mathrm{C}$ with $5 \% \mathrm{CO}_{2}$.

\section{Cytocompatibility evaluation}

The lactate dehydrogenase (LDH) release assay (Sigma Aldrich, TOX7 kit) and PrestoBlue cell viability assay (Thermo Fisher Scientific) were performed to assess nanoparticles behaviour. All cells were seeded at $1 \times 10^{4}$ cells per well in 96 well plates and cultured for 24 hours prior to assaying. Nanoparticles were exposed to cells for 48 hours and applied in $100 \mu \mathrm{l}$ phenol red free DMEM containing $10 \%(\mathrm{v} / \mathrm{v})$ FBS and $2 \mathrm{mM}$ L-glutamine. Triton X-100 (TX) applied at 1\% (v/v) applied in phenol red free medium was used as a cell death (positive) control and a vehicle control containing no nanoparticles used as a negative control. Following exposure, $50 \mu \mathrm{l}$ of supernatant was collected per well for analysis of LDH content. Cells were then washed twice with warm PBS and $100 \mu 10 \%$ $(\mathrm{v} / \mathrm{v})$ PrestoBlue reagent diluted in phenol red free medium applied per well for 60 minutes. The resulting fluorescence was measured at $560 / 600 \mathrm{~nm}\left(\lambda_{\mathrm{ex}} / \lambda_{\mathrm{em}}\right)$. Relative metabolic activity was calculated by setting values from the negative control as $100 \%$ and positive control values as $0 \%$ metabolic activity. Assessment of LDH release was performed according to the manufacturer's instructions and involved adding $100 \mu \mathrm{LDH}$ reagent to collected supernatant samples and incubating at room temperature shielded from light for 25 minutes. Absorbance was then measured at $492 \mathrm{~nm}$. Relative LDH release was calculated with the negative control absorbance at $492 \mathrm{~nm}$ taken as $0 \%$, and the positive control, assumed to cause total cell lysis, as $100 \%$. 


\section{Results and Discussion}

\section{ROP of LA initiated by geraniol in 2-MeTHF with DCM.}

The solubility of the library of monoterpene initiators was evaluated in DCM to show that geraniol (ger) limonene-alcohol (lim) and carveol (car) were readily soluble at room temperature. The transsobrerol ( $t$-sob) was not soluble, which was unsurprising as this molecule is water-soluble and known to be poorly soluble in organic solvents,[40] likely due to the higher polarity conferred to the molecule by the additional unreactive tertiary hydroxyl group (compared to the other terpene heads). 2-MeTHF has a much higher boiling point $\left(80^{\circ} \mathrm{C}\right)$ than $\mathrm{DCM}$, allowing us to operate at a higher temperature. We found that at $60^{\circ} \mathrm{C}$ all of the initiators and monomer were dissolved. This temperature was thus set as the reaction temperature for the ROP synthetic steps in 2-MeTHF, thereby overcoming any solubility limitations and adding a new terpene- $\mathrm{OH}$ to the library of initiators available for use in the ROP process. The initiator ger was used to produce PDLLA oligomers in both DCM and 2-MeTHF (Figure S1) and 20 minutes after DBU addition and reaction activation, both of the reaction mixtures (DCM and 2-MeTHF) were added dropwise into cold heptane. The resulting precipitates were purified via additional washing steps. The DCM reaction was simply adopted as a comparison to establish the quality of the oligomer produced in 2-MeTHF. ATR-IR spectra of the two hybrid oligomers (from DCM and 2-MeTHF - Figure S2) resulted superimposable, confirming qualitatively the success of the reactions and the similarity of the final products from the two reactions. In particular, the sharp transition at $1750 \mathrm{~cm}^{-1}$ is related to the $\mathrm{C}=0$ stretching of the PDLLA ester peak whilst the $\mathrm{C}=\mathrm{C}$ stretching of the alkene in the terpene initiator is at around $1650 \mathrm{~cm}^{-1}$ (Figure S2). In both solvents, a similar conversion of LA (final DP=7) into the related oligomers after the same timeframe was observed (Figure 1 and S1). Peak shifts and broadening that are associated with polymerisation were observed (Figure S3), and were comparable for both reaction conditions, in particular for the monomer $\mathrm{CH}$ and $\mathrm{CH}_{3}$ peaks (at 5.25 and $1.65 \mathrm{ppm}$ respectively) and the initiator alkene peaks (between $5.30 \mathrm{ppm}$ and $5.10 \mathrm{ppm}$ ). 
10<smiles>CC(C)=CCC/C(C)=C/CO</smiles>

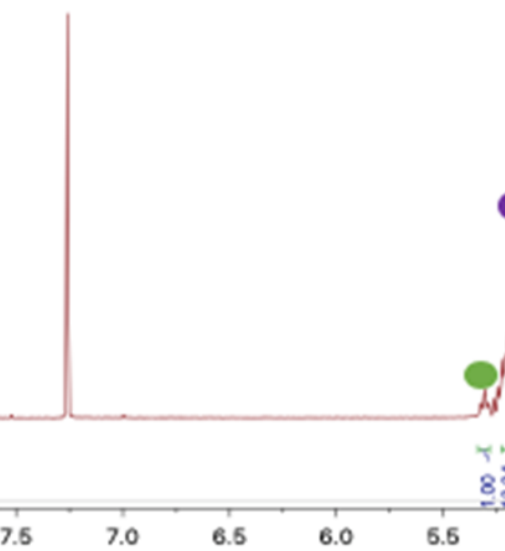

\section{8 สำ}

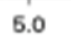

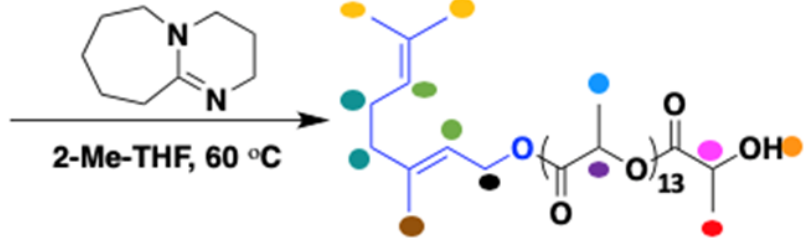

* DBU

* 2-MeTHF

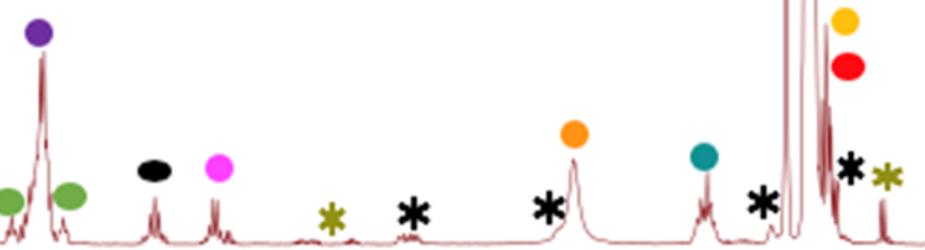

4.0
11 (opm)

3.5

$2.6 \quad 2.0$

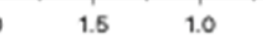

Figure 1. (Above) Reaction scheme of ger-initiated PDLLA 10 ROP in 2-MeTHF. (Below) ${ }^{1} \mathrm{H}-\mathrm{NMR}$ of the final purified oligomers and main macromolecule peak assignments. The targeted DP (ideal number of LA units in the final oligomer) was 10, as reported in the stoichiometry of the monomer in Figure 1 (Above). Due to a conversion of $70 \%$ of monomer into polymer a DP of 7 was registered by ${ }^{1} \mathrm{HNMR}$. Polylactide structure was conventionally reported as half unit (Figure 1 Above). In this case the number of $\mathrm{LA} C H$ protons is equal to the number of repetitive units. However, LA bears two protons per full unit and thus the final DP is considered dividing by two the total number of LA CH protons. 
Table1. Chemical and physical characterisations of terpene-initiated PDLLA oligomers synthesised in 2-MeTHF.

\begin{tabular}{|c|c|c|c|c|c|c|c|c|}
\hline Polymer & $\mathrm{DP}_{\mathrm{n}}{ }^{*}(\mathrm{NMR})$ & Conversion $^{* *}(\%)$ & $\begin{array}{l}\mathrm{Mn}^{* * *} \\
\text { (NMR) }\end{array}$ & $\begin{array}{l}\mathrm{M}_{\mathrm{n}}^{* * * *} \\
(\mathrm{GPC})\end{array}$ & Ð & $\begin{array}{l}\mathrm{T}_{\mathrm{g}} \\
\text { (DSC) } \\
\left({ }^{\circ} \mathrm{C}\right)\end{array}$ & $\begin{array}{l}T_{g} \\
\text { (DMA) } \\
(1 \mathrm{~Hz}) \\
\left({ }^{\circ} \mathrm{C}\right)\end{array}$ & $\begin{array}{l}\text { Water } \\
\text { Contact } \\
\text { Angle } \\
\Theta_{w}\left({ }^{\circ}\right)\end{array}$ \\
\hline car-LA 10 & $\begin{array}{l}10 \text { (20 LA CH } \\
\text { units) }\end{array}$ & full & 1700 & 2100 & 1.2 & 13.5 & 20.2 & $72 \pm 2$ \\
\hline ger-LA 10 & $\begin{array}{llll}7 \quad \text { (14 } & \text { LA } & \text { CH } \\
\text { units) } & & \end{array}$ & 70 & 1150 & 1330 & 1.2 & -4.6 & 0.3 & $65 \pm 4$ \\
\hline $\lim -\mathrm{LA}_{10}$ & $\begin{array}{llll}8 & \text { (16 } & \text { LA } & \mathrm{CH} \\
\text { units) } & & \\
\end{array}$ & 80 & 1300 & 1670 & 1.2 & 25.7 & 31.3 & $68 \pm 1$ \\
\hline$t$-sob-LA 10 & $\begin{array}{l}10 \text { (20 LA CH } \\
\text { units) }\end{array}$ & full & 1600 & 2050 & 1.2 & 24.4 & 26.0 & $55 \pm 3$ \\
\hline
\end{tabular}

* DP values approximated to the closest whole values and related number of $\mathrm{CH}$ on the LA chain

** Calculated from ${ }^{1} \mathrm{H}-\mathrm{NMR}$

*** Calculated from alkene (terpene, initiator) peak and methine PDLLA peak ${ }^{1} \mathrm{H}-\mathrm{NMR}$ integration.

**** Compared to PDLLA standards

Lactide ROP with the full monoterpene initiators library in 2-MeTHF

Following the success of the 2-MeTHF method for the geraniol-initiated ROP of LA, the full available library of hydroxyl monoterpenes was subsequently tested for the ring opening initiation of lactide in this solvent. The ${ }^{1} \mathrm{H}$ NMR spectra of each of the final oligomers (Figure $\mathrm{S} 4$ ) shows the retention of all of the characteristic peaks of both the polymerised lactide and terpene initiators. As shown in Table 1, the reaction conversions ranged from $70 \%$ to full conversion. $M_{n}$ values were calculated by comparing the integrations of the terpene alkene peaks (Figure S4 and Figure 1), in the spectra range between 5.50 and $5.00 \mathrm{ppm}$ according to the different terpene adopted (green dots) and the $\mathrm{CH}$ peak of the PDLLA chain at $5.25 \mathrm{ppm}$ (violet dot). The similarity between the theoretical $\mathrm{M}_{\mathrm{n}}$ values calculated via NMR and GPC confirmed the retention of the initiator and monomer ratios, corroborating the stoichiometric integration of the alkene initiator peak and the methine group of the monomer.[22] In addition, the quality of the reaction can be evaluated by considering the low dispersity ( $Đ$ ) observed in all the tested materials $(\leq 1.3)$ and the presence of a single molecular weight peak distribution (Figure S5).

Thermal and dynamic mechanical analysis confirmed the amorphous nature of the synthesised oligomers (Table 1). Both DSC and DMA showed the same $T_{g}$ trend among the four materials. Though differences can be observed between the two analyses, these are due to the intrinsic difference between the static DSC and the dynamic DMA measurement, resulting in the DSC observed $\mathrm{Tg}_{\mathrm{g}}$ being 
lower in absolute values. [41] By maintaining a similar molecular weight in the final oligomers, the main factor impacting on the $\mathrm{T}_{\mathrm{g}}$ values is likely to be the nature of the initiator, namely the terpene-head. $T_{g}$ values ranging from -4.6 to $25.7^{\circ} \mathrm{C}$ were measured by DSC while $T_{g} s$ ranging from 0.3 to 31.3 were detected by DMA (Table 1). However, the same final trend throughout the samples was observed with lim- $\mathrm{LA}_{10}$ showing the highest transition and ger- $\mathrm{LA}_{10}$ the lowest transition. Contact angle values can be considered as a measure of the hydrophobic/hydrophilic character of a particular surface on the length scale of the water droplet. A surface can be considered hydrophobic when $\Theta>90^{\circ}$ and hydrophilic when $\Theta<90^{\circ}$.[42] Each of the surfaces showed a good wettability with $\Theta_{w}$ below the $90^{\circ}$ hydrophobicity threshold with values spanning from circa $72^{\circ}$ to $55^{\circ}$ (Table 1 ). This evidence supported the amphiphilic chemical nature of the molecules suggesting a possible rearrangement of the hydroxyl end group towards the water droplets and the segregation of the lactide short chain and terpene head towards the inner part of the film. In fact, reported $\Theta_{w}$ values for non-functionalised PDLLA with a longer chain ranged from around $80^{\circ}$ up to around $90^{\circ}$ confirming a hydrophilic/hydrophobic balance of these short oligomers. $[43,44]$ Interestingly, $t$-sob-LA 10 , resulted in the most "hydrophilic" terpene head showing the lowest $\Theta_{w}$ thus, indirectly hinting at the preservation of the extra free tertiary hydroxyl group that may contribute to the improvement of the surface wettability (higher hydrophilicity compared to the other terpene heads).[45] On the basis of this solid-liquid interface rearrangement ability and based on previous literature showing the ability of lactide retinol-initiated polymers to self-assemble in water,[22] we tested our library of oligomers via nanoprecipitation.

Table 2. Nanoparticles size, size distribution and Z-potential.

\begin{tabular}{|c|c|c|c|}
\hline Polymer & Size $(\mathbf{n m})$ & PDI & $\begin{array}{c}\text { Z-potential } \\
(\mathbf{m V})\end{array}$ \\
\hline car-LA 10 & $231 \pm 4$ & $0.11 \pm 0.03$ & $-21 \pm 2$ \\
\hline ger-LA 10 & $201 \pm 8$ & $0.08 \pm 0.02$ & $-32 \pm 3$ \\
\hline lim-LA 10 & $195 \pm 3$ & $0.04 \pm 0.01$ & $-31 \pm 3$ \\
\hline t-sob-LA & $176 \pm 5$ & $0.03 \pm 0.02$ & $-27 \pm 4$ \\
\hline
\end{tabular}

Measures performed in milliQ grade water.

\section{Self-assembling characterisation}

All the materials were able to self-assemble in water into well-defined NPs, with diameters ranging from circa $230 \mathrm{~nm}$ up to $175 \mathrm{~nm}$ and very narrow PDIs consistently below 0.1 (Table 2). The highly negative Z-potential for all the nanosystems may be a result of the segregation of the free hydroxyl end groups towards the NPs surface. In the nanoprecipitation step the oligomers self-assembled into nanoaggregates without using additional stabilisers, envisaging the potential of these materials to be considered as renewable and biodegradable surfactants. Additionally, due its high hydrophobicity, PDLLA, at higher molecular weight, cannot self-assemble into nanoparticles unless copolymerised with a second highly hydrophilic (macro)molecule (e.g. PEG), highlighting the quality and advantage of our one-step green reaction.[46] Interestingly, $t$-sob-LA 10 showed the smallest NPs sizes (up to $60 \mathrm{~nm}$ smaller than the others), likely due to the more pronounced amphiphilic balance with the hydrophobic lactide chain due to the presence of a second free hydroxyl moiety from the head group. This again 
highlights another advantage of our switch from DCM to 2-MeTHF: not only does it allow for the generation of these oligomers through a more green and sustainable process, but it also enables the solubility of $t$-sob, which has given us to access these unique terpenoid-based NPs.

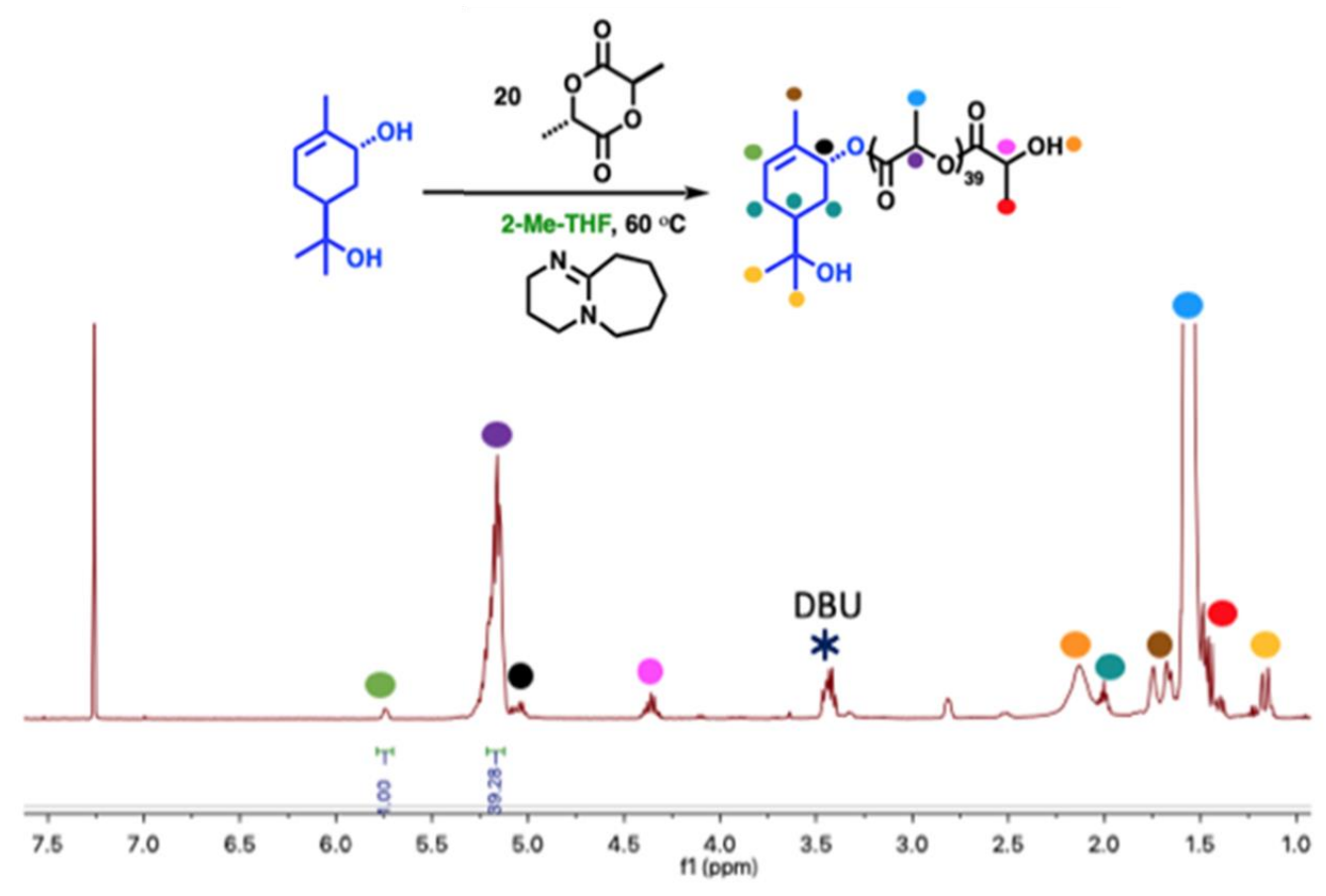

Figure 2. (Top) Reaction scheme of $t$-sob-LA ${ }_{20}$. (Bottom) ${ }^{1} \mathrm{H}-\mathrm{NMR} t$-sob-LA ${ }_{20}$, peaks assignment and integration for experimental $D P_{n}$ evaluation.

\section{Effect on LA length on $t$-sob initiated oligomers}

This experimental evidence led us to explore further LA-based polymers bearing the hydrophilic $t$-sob group by tuning the $\mathrm{M} / \mathrm{I}$ ratio (Figure 2 ). In addition to $t$-sob-LA $\mathrm{LA}_{10}, t$-sob- $\mathrm{LA}_{20}$ (bearing $20 \mathrm{LA}$ units) has been synthesised and characterised. There is a reasonable relationship between the monomer/initiator feed-ratio (20/1) and the final number of LA units in the polymer (DPn 20) (Figure 2). Additionally, the retention of all the peaks related to the terpene backbone confirm the robustness of the greener reaction conditions adopted. Also, the longer polymer showed a narrow monomodal GPC trace confirming a single molecular weight distribution of $2200 \mathrm{Da}$ and $Ð$ of 1.3. By almost doubling the length of the PDLLA chain, it has been possible to tune the amphiphilicity, balancing the longer polymer chain hydrophobicity with the polar terpene-head (due to $t$-sob free tertiary hydroxyl group). In fact, $t$-sob-LA 20 self-assembled in water, producing well-defined NPs (Figure 3 ) with size around $103 \mathrm{~nm}, \mathrm{PDI}$ of 0.12 and a Z-potential of circa $-40 \mathrm{mV}$. This nanoaggregate resulted almost 70 $\mathrm{nm}$ (Figure 3) smaller than the one produced from $t$-sob-LA $\mathrm{A}_{10}$, highlighting the importance of a precise hydrophobic/hydrophilic balance.[47]

Critical Aggregation Concentrations (CACs) were calculated by plotting the light scattering count rate intensity variation related to serial dilution concentrations. The resulting CAC values were circa $90 \mu \mathrm{g} \mathrm{mL} \mathrm{L}^{-1}$ for $t$-Sob-LA $10(0.053 \mathrm{mM})$ and $70 \mu \mathrm{gL}^{-1}$ for $t$-Sob-LA 20 (0.032 mM) (Figure 3, Right). These 
values are comparable to the critical micelle concentration (CMC) of commonly used surfactants, such as Triton X100 and Tween 20, which present CMC values of 0.22-0.24 mM and 0.049 mM (Sigma Aldrich Merck catalogues) respectively. The experimentally calculated CAC results, found for the two terpene-initiated polylactides, indicated that NPs can be present at low concentration in the final suspensions and required high dilution before disaggregation occurred, broadening the field of applications for these novel materials e.g. as functionalised polymeric drug delivery carriers.

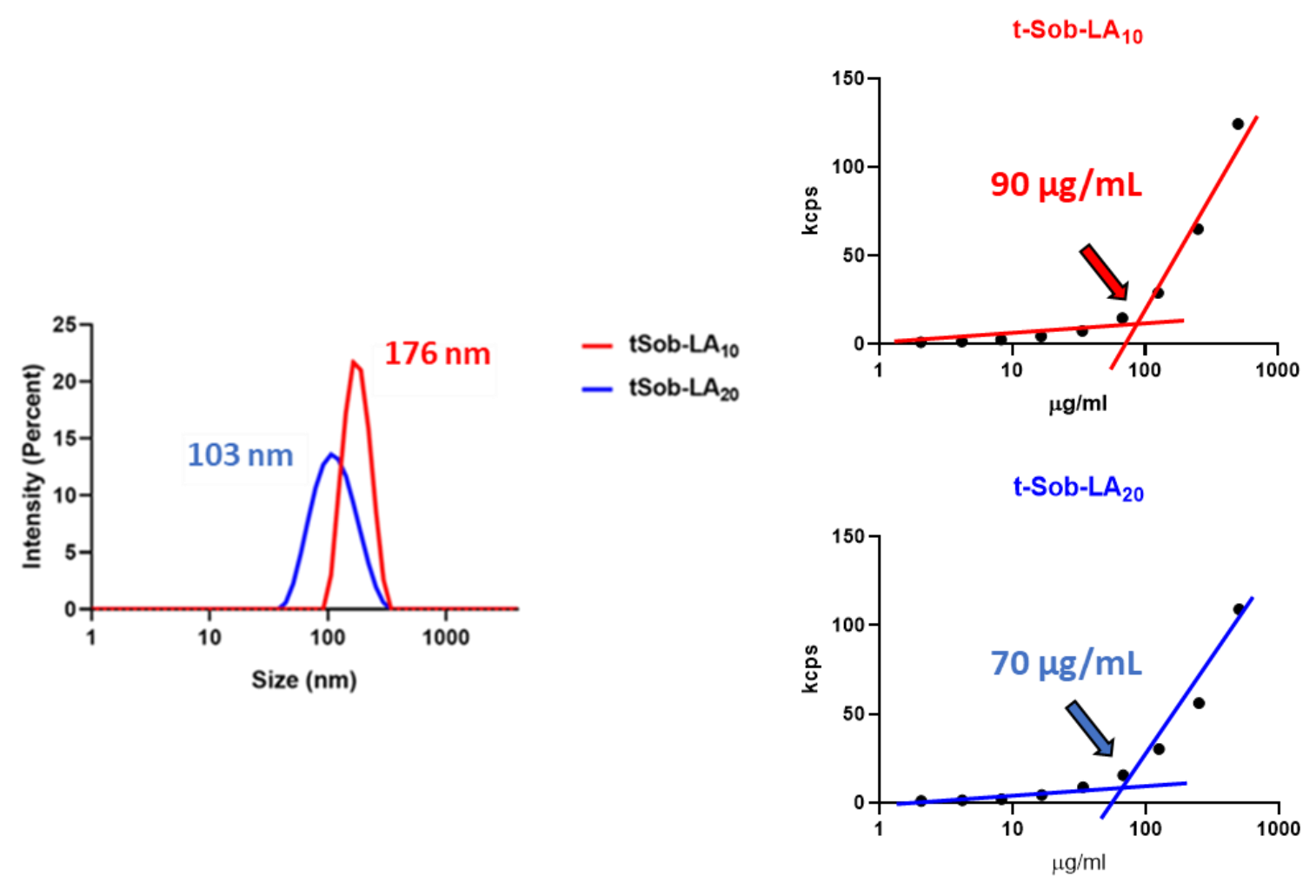

Figure 3. DLS Intensity of NPs formed from $t$-sob-LA $A_{10}$ and $t$-sob-LA $A_{20}$ (Left). Critical aggregation concentration (CAC) graphs of count rate in kcps vs concentration $(\mu \mathrm{g} / \mathrm{mL})$ of t-sob-LA $10(0.053 \mathrm{mM})$ and t-sob-LA 20 (0.032 mM) (Right).

To further highlight the importance of the nature of the different moieties present on the terpene headgroups upon the final nanoparticle suspensions, a test of stability in phosphate buffer (PBS) (at $\mathrm{pH}$ 7.4) was performed. NPs prepared from lim- $\mathrm{LA}_{10}$ (no free $\mathrm{OH}$ on the terpene head) and $t$-sob-LA $\mathrm{A}_{20}$ (presence of a free tertiary $\mathrm{OH}$ in the terpene head) were used as model colloids and their size average variation was monitored up to $48 \mathrm{~h}$ after dilution with PBS, at a concentration of $500 \mu \mathrm{g} / \mathrm{mL}$. As depicted in Figure S6, the average sizes of $\lim -\mathrm{LA}_{10}$ NPs tended to be stable up to $24 \mathrm{~h}$ of incubation in PBS while agglomeration and aggregation can be observed after $48 \mathrm{~h}$ of incubation, indicating 
destabilisations likely due to the altered ionic strength of the medium. On the other hand, $t$-sob-LA 20 showed high stability throughout the $48 \mathrm{~h}$ of observation window, highlighting the stabilisation effect, due to the free tertiary $\mathrm{OH}$ and a more precise amphiphilic balancing (due to a longer LA chain), in media that mimics more relevant biological environments.

\section{Cytotoxicity assessment of the terpene initiated PDLLA oligomers library}

In vitro preliminary cytotoxicity screening was performed on Caco-2 intestinal, A549 lung and A431 skin cells to represent exposure via ingestion, inhalation and skin contact, respectively. Each of the produced surfactants was tested on cells at a concentration of $1 \mathrm{mg} \mathrm{mL}^{-1}$ in cell culture medium containing $10 \%$ of FBS. Each of the particles showed no cytotoxicity in both assays carried out and in all cell types studied similarly to the vehicle control DMEM. This included no drop in metabolic activity over 48 hours (Figure 4A), and no membrane disruption compared to the surfactant control TritonX100 (Figure 4B). The absence of cytotoxicity indicates the materials can be considered biocompatible and thus, combined with the known biodegradability of lactide-based polymers, these show promising potential for the adoption of these materials as carriers in drug delivery or other biomedical applications.
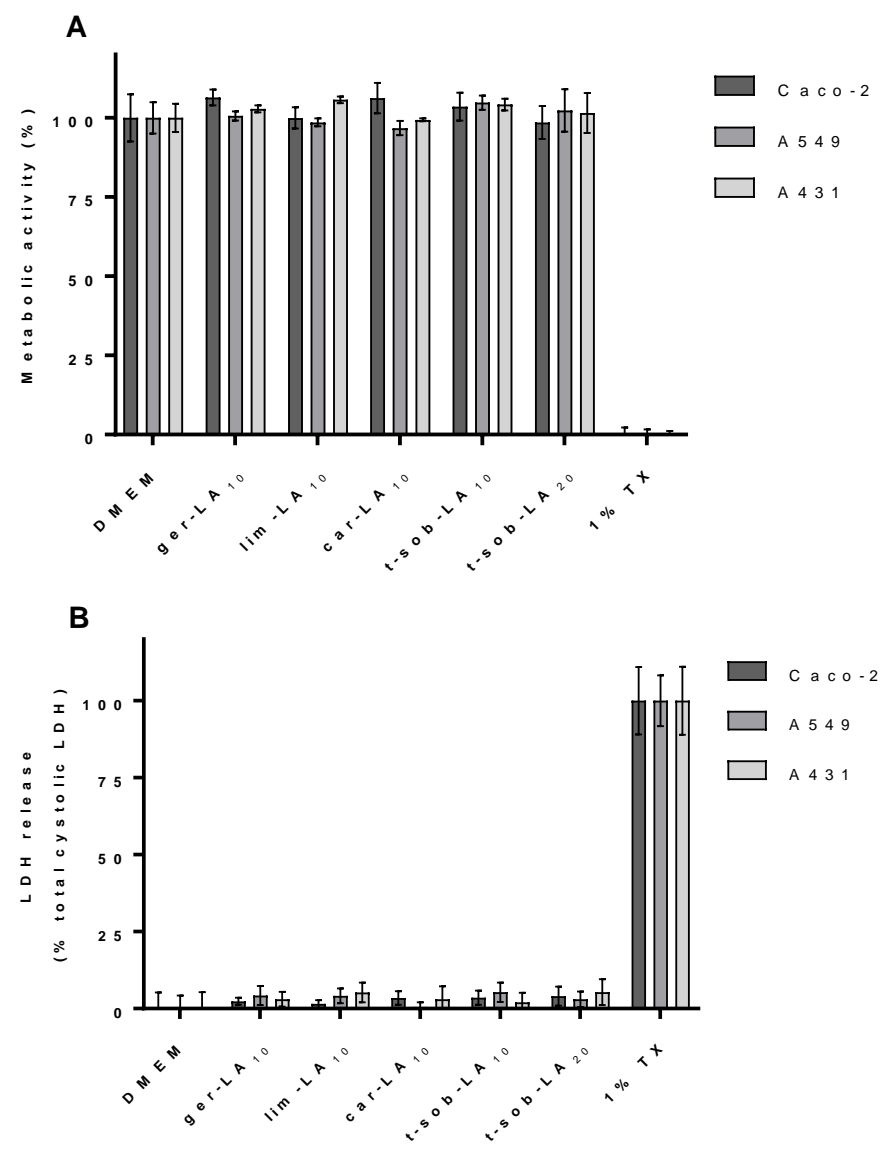

Figure 4. Biocompatibility of NPs on Caco-2 (intestinal), A549 (airway) and A431 (skin) epithelial cells. Cytotoxicity was determined by PrestoBlue metabolic activity and LDH release as an indicator of membrane damage. Particles $(1 \mathrm{mg} / \mathrm{mL})$ were applied to cells in $10 \%$ FBS containing DMEM and 
exposed for 48 hours to cells. All cells were seeded at a density of $1.2 \times 10^{5}$ cell per well, and cultured for 24 hours prior to assaying. DMEM treatment represents the vehicle control and Triton X-100 (TX) applied at $1 \%(v / v)$ was used as the cell death control. Data are presented as mean \pm S.D $(n=3)$.

The desirable alkene moiety was retained and the targeted PDLLA chain length was obtained as revealed by the combination of ${ }^{1} \mathrm{H}-\mathrm{NMR}$ analysis and GPC data (Experimental Section and Table 1). Therefore, from this first comparison it can be concluded that the higher boiling point 2-MeTHF leads to an improvement in terms of solubility beyond what can be achieved in DCM due to, thus broadening the pool of molecules that may be employed in ROP synthesis. Additionally, we have demonstrated a facile method to avoid the use of chlorinated or fossil-fuel derived solvents producing highly biocompatible and biorenewable functionalised surfactants with promising properties for bio and pharma applications. In particular, due to the smaller size and higher stability of the NPs bearing $t$-sob moiety, compared to the rest of the library, this material may be envisaged as oligomeric carrier in the field of the drug delivery. It is known that negative zeta potentials further reduce nonspecific uptake into the liver and spleen due to electrostatic repulsion between the particles and the cellular surface increasing blood circulation. Therefore, the low toxicity and the negative potential may be exploited to produce stealth nanocarriers bearing novel functionalities [48]

\section{Conclusions}

We have designed a library of terpene-initiated lactide oligomers that align with the concept of a circular economy and using renewable materials to generate biocompatible surfactants.

We have demonstrated, for the first time, that 2-MeTHF is an effective, greener alternative to DCM as a reaction solvent for the ring opening polymerisation of lactide. In addition to the improved greener reaction conditions, we have employed a small library of terpene molecules bearing hydroxyl functionalities, to provide functionalisable, renewably sourced initiators for ROP. The use of 2-MeTHF has allowed this library to expand and include the use of trans-sobrerol, insoluble in DCM at room temperature but readily soluble in $2-\mathrm{MeTHF}$ at $\sim 60{ }^{\circ} \mathrm{C}$. The geraniol-initiated oligomer ( $\mathrm{LA}_{10}$ units) produced in the green solvent was comparable to the oligomer species prepared in DCM in terms of monomer to polymer conversion, NMR and GPC molecular weights. The whole set of terpene initiators (car, ger, lim and $t$-sob) was then used to produce PDLLA oligomers with targeted 10 repeat units in 2-MeTHF.

The retention of the "terpenoid double bond" motif was confirmed by IR and ${ }^{1} \mathrm{H}$ NMR for each oligomer independent from the nature of the initiator. The presence of this alkene group in the headgroup of the bio-hybrid polyesters could therefore be further exploited as a versatile dockingpoint for the production of highly functionalisable, degradable polymeric platforms. Interestingly, these new materials self-assembled in water producing well defined nanoparticles (NPs) via direct nanoprecipitation without the use of additional stabilisers. The final self-assembling aggregates were 
studied by employing DLS and Z-potential. To further demonstrate the robustness of both the reaction medium and conditions, a 20 LA-unit polymer was synthesised employing $t$-sob as an initiator. By altering the length of the PDLLA chain we demonstrated the tuning of the amphiphilic balance between the t-sob head, bearing a tertiary hydroxyl group (thus, resulting the most polar among the terpenes used) and the hydrophobic polyester backbone and smaller NPs (around $100 \mathrm{~nm}$ ) were formulated with CAC values comparable to marketable surfactants.

These nanoparticles were devoid of any major cytotoxicity, hinting at their potential use as biomaterials. These monoterpenes can be considered a tool-box of renewable and highly functionalisable small molecules for a new generation of ROP initiators, and the use of 2-MeTHF can render a more sustainable ROP synthesis. By showing the potential for these oligomers/polymers as surfactants, we hope to motivate more research groups to embrace the concept of the circular economy and renewable materials.

\section{Conflicts of interest}

There are no conflicts of interest to declare.

\section{Acknowledgements}

This work was supported by the Engineering and Physical Sciences Research Council [grant numbers EP/N019784/1, EP/N006615/1 and EP/N03371X/1]; the School of Chemistry, University of Nottingham and the Royal Society [Wolfson Research Merit Award WM150086].

\section{Notes and References}

[1] Ellen MacArthur Foundation, The New Plastics Economy: Rethinking the future of plastics, 2016. http://www3.weforum.org/docs/WEF_The_New_Plastics_Economy.pdf (accessed May 14, 2017).

[2] M. Peplow, Plastic Fantastic, Nature. 536 (2016) 266-268. https://doi.org/10.1038/536266a.

[3] M. Okada, Chemical syntheses of biodegradable polymers, Prog. Polym. Sci. 27 (2002) 87133. https://doi.org/10.1016/S0079-6700(01)00039-9.

[4] I. Faye, M. Decostanzi, Y. Ecochard, S. Caillol, Eugenol bio-based epoxy thermosets: from clove to applied materials, Green Chem. 19 (2017) 5236-5242.

https://doi.org/10.1039/C7GC02322G.

[5] A.H. Tullo, Fighting Ocean Plastics at the Source, Chem. Eng. News. 96 (2018) 29-34.

[6] C. Williams, M. Hillmyer, Polymers from Renewable Resources: A Perspective for a Special Issue of Polymer Reviews, Polym. Rev. 48 (2008) 1-10.

https://doi.org/10.1080/15583720701834133.

[7] M.R. Thomsett, R.A. Stockman, T.E. Storr, S.M. Howdle, O.R. Monaghan, Progress in the synthesis of sustainable polymers from terpenes and terpenoids, Green Mater. 4 (2016) 115134. https://doi.org/10.1680/jgrma.16.00009.

[8] D.M. O’Brien, C. Vallieres, C. Alexander, S.M. Howdle, R.A. Stockman, S. V. Avery, Epoxy- 
amine oligomers from terpenes with applications in synergistic antifungal treatments, $\mathrm{J}$. Mater. Chem. B. 7 (2019) 5222-5229. https://doi.org/10.1039/c9tb00878k.

[9] M. Belgacem, A. Gandini, Monomers, Polymers and Composites from Renewable Resources, in: M. Naceur Belgacem, A. Gandini (Eds.), Monomers, Polym. Compos. from Renew. Resour., 1st ed., Elsevier Ltd., Oxford, 2008: pp. 17-38. https://doi.org/10.1016/B978-0-08-0453163.00013-2.

[10] G. Reuss, W. Disteldorf, A.O. Gamer, A. Hilt, Flavors and Frangrances, Ulmann's Encycl. Ind. Chem. 15 (2012) 735-768. https://doi.org/10.1002/14356007.a11.

[11] P. Sahu, P. Sarkar, A.K. Bhowmick, Synthesis and Characterization of a Terpene-Based Sustainable Polymer: Poly-alloocimene, ACS Sustain. Chem. Eng. 5 (2017) 7659-7669. https://doi.org/10.1021/acssuschemeng.7b00990.

[12] M.F. Sainz, J.A. Souto, D. Regentova, M.K.G. Johansson, S.T. Timhagen, D.J. Irvine, P. Buijsen, C.E. Koning, R.A. Stockman, S.M. Howdle, A facile and green route to terpene derived acrylate and methacrylate monomers and simple free radical polymerisation to yield new renewable polymers and coatings, Polym. Chem. 7 (2016) 2882-2887. https://doi.org/10.1039/C6PY00357E.

[13] C.M. Byrne, S.D. Allen, E.B. Lobkovsky, G.W. Coates, Alternating copolymerization of limonene oxide and carbon dioxide, J Am Chem Soc. 126 (2004) 11404-11405. https://doi.org/10.1021/ja0472580.

[14] M.A. Droesbeke, F.E. Du Prez, Sustainable Synthesis of Renewable Terpenoid-Based (Meth)acrylates Using the CHEM21 Green Metrics Toolkit, ACS Sustain. Chem. Eng. 7 (2019) 11633-11639. https://doi.org/10.1021/acssuschemeng.9b01578.

[15] A. Llevot, P.K. Dannecker, M. von Czapiewski, L.C. Over, Z. Soyler, M.A.R. Meier, Renewability is not Enough: Recent Advances in the Sustainable Synthesis of Biomass-Derived Monomers and Polymers, Chem. - A Eur. J. 22 (2016) 11510-11521.

https://doi.org/10.1002/chem.201602068.

[16] K. Yao, C. Tang, Controlled polymerization of next-generation renewable monomers and beyond, Macromolecules. 46 (2013) 1689-1712. https://doi.org/10.1021/ma3019574.

[17] D. Zhang, M.A. Hillmyer, W.B. Tolman, Catalytic polymerization of a cyclic ester derived from a "cool" natural precursor, Biomacromolecules. 6 (2005) 2091-2095. https://doi.org/10.1021/bm050076t.

[18] H.C. Quilter, M. Hutchby, M.G. Davidson, M.D. Jones, Polymerisation of a terpene-derived lactone: A bio-based alternative to $\epsilon$-caprolactone, Polym. Chem. 8 (2017) 833-837. https://doi.org/10.1039/c6py02033j.

[19] M. Winnacker, J. Sag, A. Tischner, B. Rieger, Sustainable, Stereoregular, and Optically Active Polyamides via Cationic Polymerization of $\varepsilon$-Lactams Derived from the Terpene $\beta$-Pinene, Macromol. Rapid Commun. 38 (2017) 1600787. https://doi.org/10.1002/marc.201600787.

[20] M. Winnacker, A.J.G. Beringer, T.F. Gronauer, H.H. Güngör, L. Reinschlüssel, B. Rieger, S.A. Sieber, Polyamide/PEG Blends as Biocompatible Biomaterials for the Convenient Regulation of Cell Adhesion and Growth, Macromol. Rapid Commun. 40 (2019) 1900091. https://doi.org/10.1002/marc.201900091.

[21] J. Zhao, H. Schlaad, S. Weidner, M. Antonietti, Synthesis of terpene-poly(ethylene oxide)s by t-BuP 4-promoted anionic ring-opening polymerization, Polym. Chem. 3 (2012) 1763-1768. https://doi.org/10.1039/c1py00388g. 
[22] I. Yildirim, T. Yildirim, D. Kalden, G. Festag, N. Fritz, C. Weber, S. Schubert, M. Westerhausen, U.S. Schubert, Retinol initiated poly(lactide)s: Stability upon polymerization and nanoparticle preparation, Polym. Chem. 8 (2017) 4378-4387. https://doi.org/10.1039/c7py00881c.

[23] M.F. Sainz, J.A. Souto, D. Regentova, M.K.G. Johansson, S.T. Timhagen, D.J. Irvine, P. Buijsen, C.E. Koning, R.A. Stockman, S.M. Howdle, A facile and green route to terpene derived acrylate and methacrylate monomers and simple free radical polymerisation to yield new renewable polymers and coatings, Polym. Chem. 7 (2016) 2882-2887.

https://doi.org/10.1039/C6PY00357E.

[24] M.S. Lima, C.S.M.F. Costa, J.F.J. Coelho, A.C. Fonseca, A.C. Serra, A simple strategy toward the substitution of styrene by sobrerol-based monomers in unsaturated polyester resins, Green Chem. 20 (2018) 4880-4890. https://doi.org/10.1039/c8gc01214h.

[25] M. Jamshidian, E.A. Tehrany, M. Imran, M. Jacquot, S. Desobry, Poly-Lactic Acid: Production, applications, nanocomposites, and release studies, Compr. Rev. Food Sci. Food Saf. 9 (2010) 552-571. https://doi.org/10.1111/j.1541-4337.2010.00126.x.

[26] S. Corneillie, M. Smet, PLA architectures: The role of branching, Polym. Chem. 6 (2015) 850867. https://doi.org/10.1039/c4py01572j.

[27] S. Inkinen, M. Hakkarainen, A.C. Albertsson, A. Södergård, From lactic acid to poly(lactic acid) (PLA): Characterization and analysis of PLA and Its precursors, Biomacromolecules. 12 (2011) 523-532. https://doi.org/10.1021/bm101302t.

[28] Y. Zhu, C. Romain, C.K. Williams, Sustainable polymers from renewable resources, Nature. 540 (2016) 354-362. https://doi.org/10.1038/nature21001.

[29] A. Mahapatro, D.K. Singh, Biodegradable nanoparticles are excellent vehicle for site directed in-vivo delivery of drugs and vaccines, J. Nanobiotechnology. 9 (2011) 55.

https://doi.org/10.1186/1477-3155-9-55.

[30] C.E. Vasey, A.K. Pearce, F. Sodano, R. Cavanagh, T. Abelha, V. Cuzzucoli Crucitti, A.B. AnaneAdjei, M. Ashford, P. Gellert, V. Taresco, C. Alexander, Amphiphilic tri- and tetra-block copolymers combining versatile functionality with facile assembly into cytocompatible nanoparticles, Biomater. Sci. 7 (2019) 3832-3845. https://doi.org/10.1039/c9bm00667b.

[31] B.G.G. Lohmeijer, R.C. Pratt, F. Leibfarth, J.W. Logan, D.A. Long, A.P. Dove, F. Nederberg, J. Choi, C. Wade, R.M. Waymouth, J.L. Hedrick, Guanidine and amidine organocatalysts for ringopening polymerization of cyclic esters, Macromolecules. 39 (2006) 8574-8583. https://doi.org/10.1021/ma0619381.

[32] R.C. Pratt, B.G.G. Lohmeijer, D.A. Long, R.M. Waymouth, J.L. Hedrick, Triazabicyclodecene: A Simple Bifunctional Organocatalyst for Acyl Transfer and Ring-Opening Polymerization of Cyclic Esters, J. Am. Chem. Soc. 128 (2006) 4556-4557. https://doi.org/10.1021/ja060662.

[33] F.P. Byrne, S. Jin, G. Paggiola, T.H.M. Petchey, J.H. Clark, T.J. Farmer, A.J. Hunt, C. Robert McElroy, J. Sherwood, Tools and techniques for solvent selection: green solvent selection guides, Sustain. Chem. Process. 4 (2016) 7. https://doi.org/10.1186/s40508-016-0051-z.

[34] A. Pellis, F.P. Byrne, J. Sherwood, M. Vastano, J.W. Comerford, T.J. Farmer, Safer bio-based solvents to replace toluene and tetrahydrofuran for the biocatalyzed synthesis of polyesters, Green Chem. 21 (2019) 1686-1694. https://doi.org/10.1039/c8gc03567a.

[35] V. Pace, P. Hoyos, L. Castoldi, P. Domínguez De María, A.R. Alcántara, 2Methyltetrahydrofuran (2-MeTHF): A biomass-derived solvent with broad application in organic chemistry, ChemSusChem. 5 (2012) 1369-1379. 
https://doi.org/10.1002/cssc.201100780.

[36] D.F. Aycock, Solvent applications of 2-methyltetrahydrofuran in organometallic and biphasic reactions, Org. Process Res. Dev. 11 (2007) 156-159. https://doi.org/10.1021/op060155c.

[37] A.K. Pearce, C.E. Vasey, A.B. Anane-Adjei, F. Sodano, V.C. Crucitti, D.J. Irvine, S.M. Howdle, C. Alexander, V. Taresco, Versatile, Highly Controlled Synthesis of Hybrid (Meth)acrylatePolyester-Carbonates and their Exploitation in Tandem Post-PolymerizationFunctionalization, Macromol. Chem. Phys. 1900270 (2019) 1900270. https://doi.org/10.1002/macp.201900270.

[38] M.H. Alvès, H. Sfeir, J.F. Tranchant, E. Gombart, G. Sagorin, S. Caillol, L. Billon, M. Save, Terpene and dextran renewable resources for the synthesis of amphiphilic biopolymers, Biomacromolecules. 15 (2014) 242-251. https://doi.org/10.1021/bm401521f.

[39] C.A. Weems, K.R. Delle Chiaie, J.C. Worch, C.J. Stubbs, A.P. Dove, Terpene- and Terpenoidbased Polymeric Resins for Stereolithography 3D Printing, Polym. Chem. (2019) 10.1039/C9PY00950G. https://doi.org/10.1039/C9PY00950G.

[40] A. Stamm, M. Tengdelius, B. Schmidt, J. Engström, P.O. Syrén, L. Fogelström, E. Malmström, Chemo-enzymatic pathways toward pinene-based renewable materials, Green Chem. 21 (2019) 2720-2731. https://doi.org/10.1039/c9gc00718k.

[41] P.G. Laye, S.B. Warrington, G.R. Heal, D.M. Price, R. Wilson, P. Haines, Principles of Thermal Analysis and Calorimetry, The Royal Society of Chemistry, 2002. https://doi.org/10.1039/9781847551764-00010.

[42] K.Y. Law, Definitions for hydrophilicity, hydrophobicity, and superhydrophobicity: Getting the basics right, J. Phys. Chem. Lett. 5 (2014) 686-688. https://doi.org/10.1021/jz402762h.

[43] H. Matsuno, R. Matsuyama, A. Yamamoto, K. Tanaka, Enhanced cellular affinity for poly(lactic acid) surfaces modified with titanium oxide, Polym. J. 47 (2015) 505-512. https://doi.org/10.1038/pj.2015.30.

[44] A.M. Pinto, S. Moreira, I.C. Gonçalves, F.M. Gama, A.M. Mendes, F.D. Magalhães, Biocompatibility of poly(lactic acid) with incorporated graphene-based materials, Colloids Surfaces B Biointerfaces. 104 (2013) 229-238.

https://doi.org/10.1016/j.colsurfb.2012.12.006.

[45] V. Taresco, J. Suksiriworapong, R. Creasey, J.C. Burley, G. Mantovani, C. Alexander, K. Treacher, J. Booth, M.C. Garnett, Properties of acyl modified poly(glycerol-adipate) comb-like polymers and their self-assembly into nanoparticles, J. Polym. Sci. Part A Polym. Chem. 54 (2016) 3267-3278. https://doi.org/10.1002/pola.28215.

[46] J.K. Oh, Polylactide (PLA)-based amphiphilic block copolymers: Synthesis, self-assembly, and biomedical applications, Soft Matter. 7 (2011) 5096-5108. https://doi.org/10.1039/c0sm01539c.

[47] H. Phan, R.I. Minut, P. McCrorie, C. Vasey, R.R. Larder, E. Krumins, M. Marlow, R. Rahman, C. Alexander, V. Taresco, A.K. Pearce, Role of self-assembly conditions and amphiphilic balance on nanoparticle formation of PEG-PDLLA copolymers in aqueous environments, J. Polym. Sci. Part A Polym. Chem. 57 (2019) 1801-1810. https://doi.org/10.1002/pola.29451.

[48] A.K. Pearce, R. K. O'Reilly, Insights into Active Targeting of Nanoparticles in Drug Delivery: Advances in Clinical Studies and Design Considerations for Cancer Nanomedicine, Bioconjugate Chem., 30 (2019) 2300-2311.https://doi.org/10.1021/acs.bioconjchem.9b00456 


\section{Support Information}

A 'greener' one-pot synthesis of monoterpene-functionalised lactide oligomers

Dara M. O'Brien, ${ }^{1+}$ Rachel L. Atkinson, ${ }^{1}{ }^{1}+$ Robert Cavanagh, ${ }^{2}$ Ana A. C. Pacheco, ${ }^{1}$ Ryan Larder,${ }^{1}$ Kristoffer Kortsen, ${ }^{1}$ Eduards Krumins, ${ }^{1}$ Alice J. Haddleton, ${ }^{1}$ Cameron Alexander, ${ }^{2}$ Robert A.

Stockman, ${ }^{1}$ Steven M. Howdle ${ }^{1}$ and Vincenzo Taresco ${ }^{1 *}$

${ }^{1}$ University of Nottingham, School of Chemistry, University Park, NG7 2RD, UK

${ }^{2}$ University of Nottingham, Department of Pharmacy, University Park, NG7 2RD, UK

${ }^{+}$These authors contributed equally

*Corresponding author: vincenzo.taresco@nottingham.ac.uk 

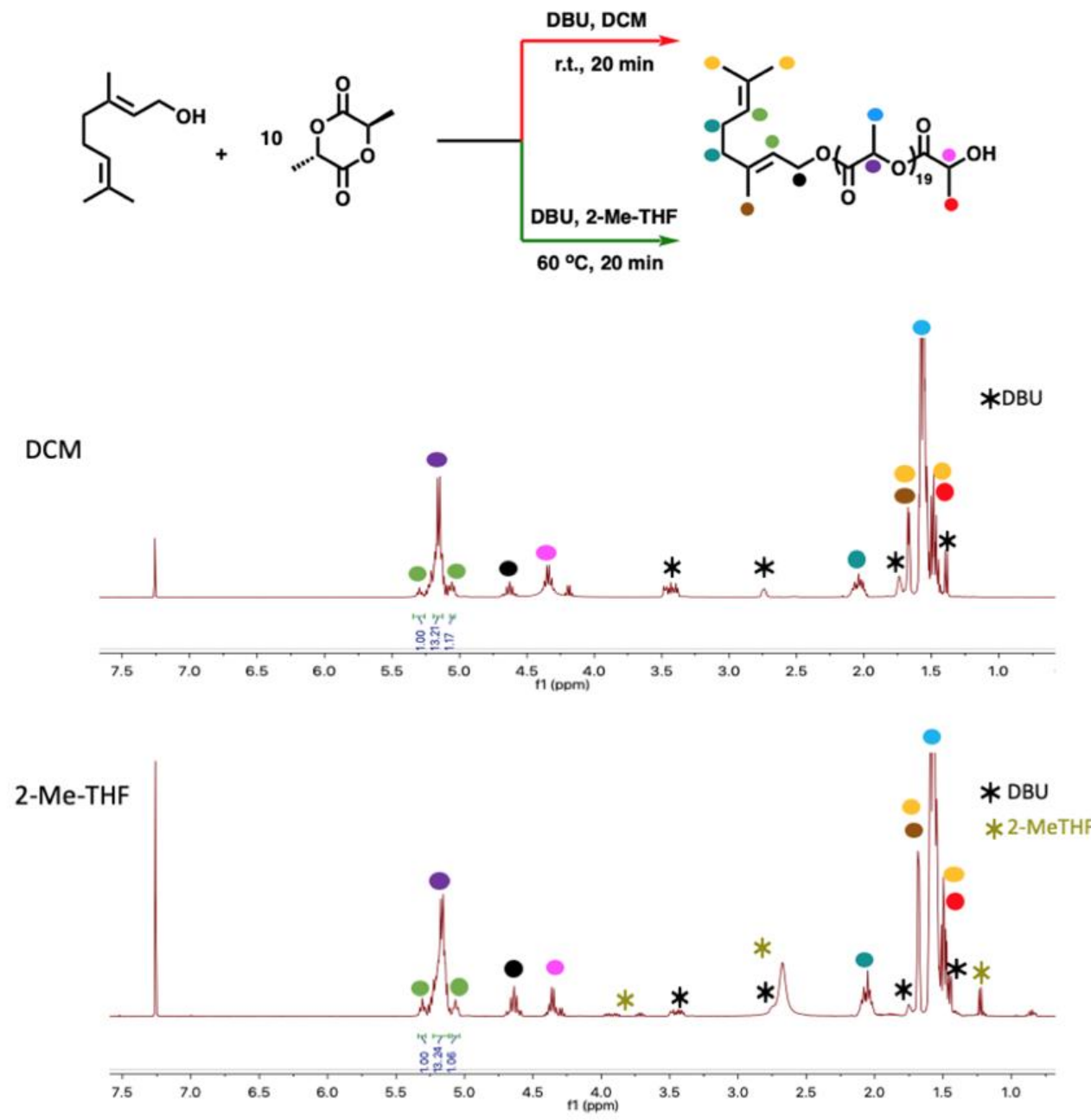

Figure S1. (Top) Synthetic scheme of gerLA $A_{10}$ in the two different reaction solvents (DCM and 2MeTHF). (Bottom) ${ }^{1} \mathrm{H}-\mathrm{NMR}$ of gerLA 10 after purification, synthesised from DCM and 2-MeTHF, peak assignments and integration for experimental $\mathrm{DP}_{\mathrm{n}}$ evaluation. 


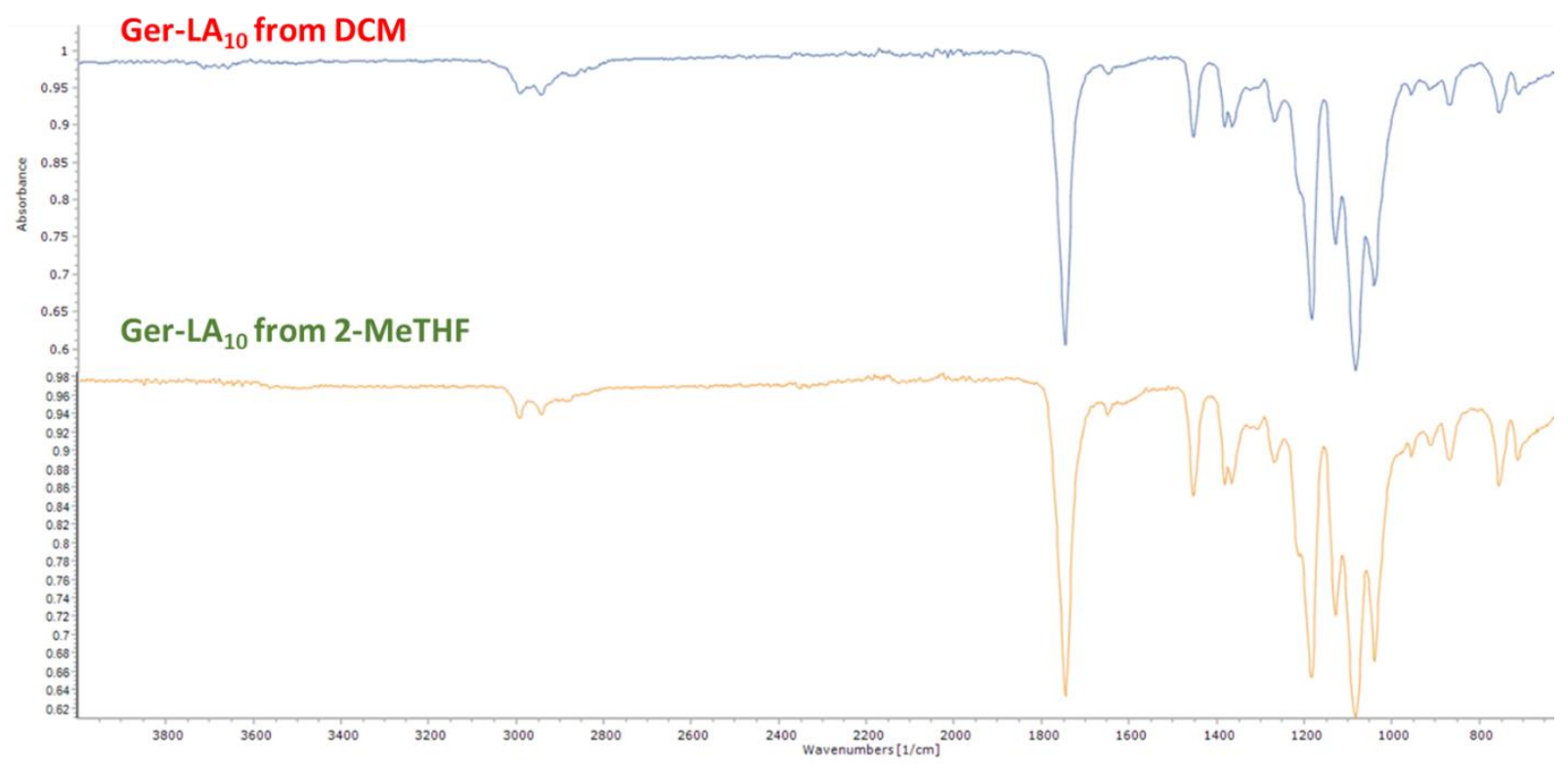

Figure S2. Stacked ATR-IR spectra of ger-LA ${ }_{10}$ oligomers synthesised in DCM and 2-MeTHF It can be observed that the two spectra are superimposable, qualitatively confirming the similarity of the final products from the two different reaction conditions. 


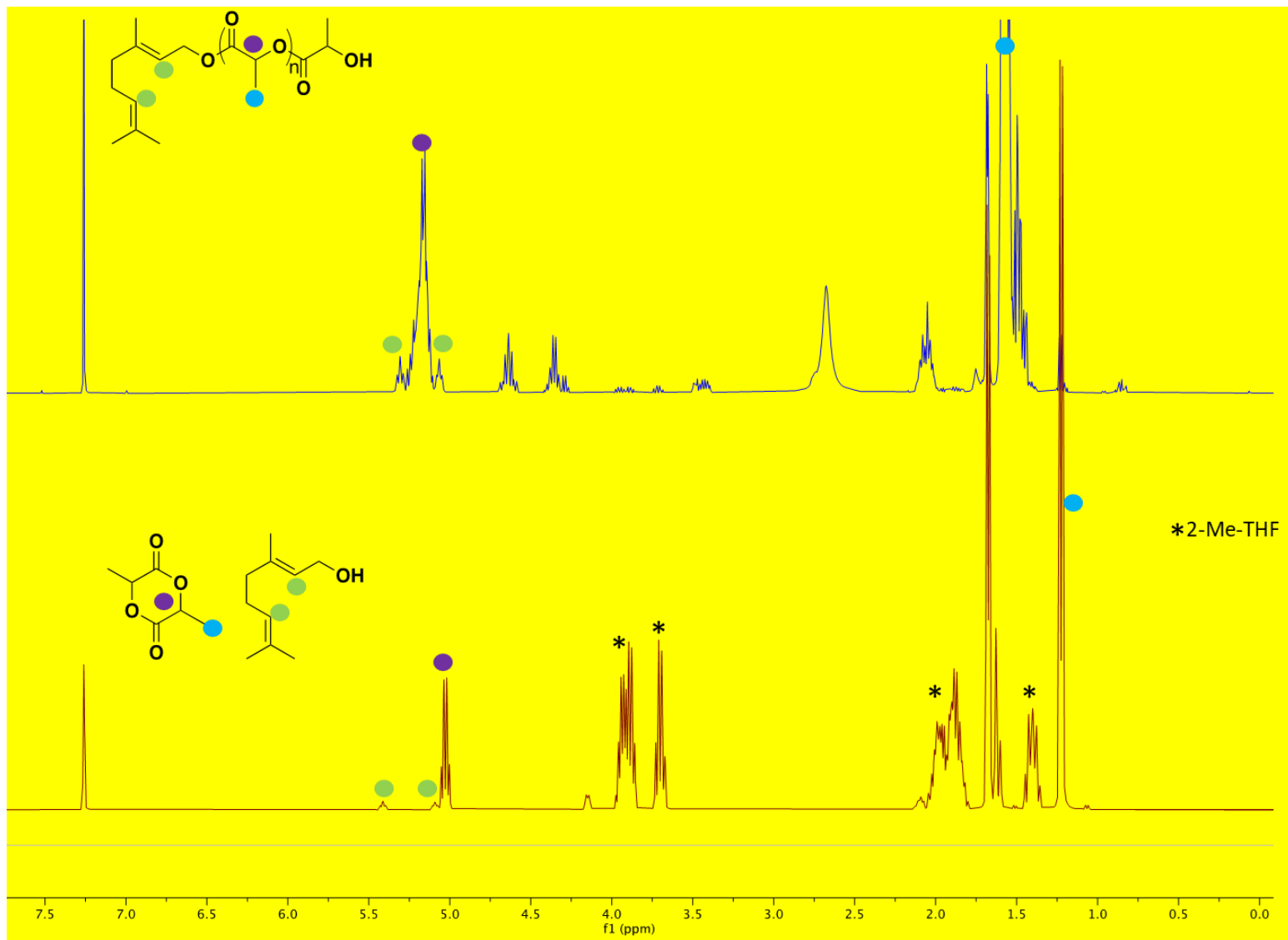

Figure S3. Stacked ${ }^{1} \mathrm{HNMR}$ spectra of the final oligomer ger-LA $\mathrm{A}_{10}$ (TOP) and mixture of the related starting materials in 2-THF (BOTTOM). Main peaks variations (chemical shifts and shape) before and after reaction have been highlighted. 


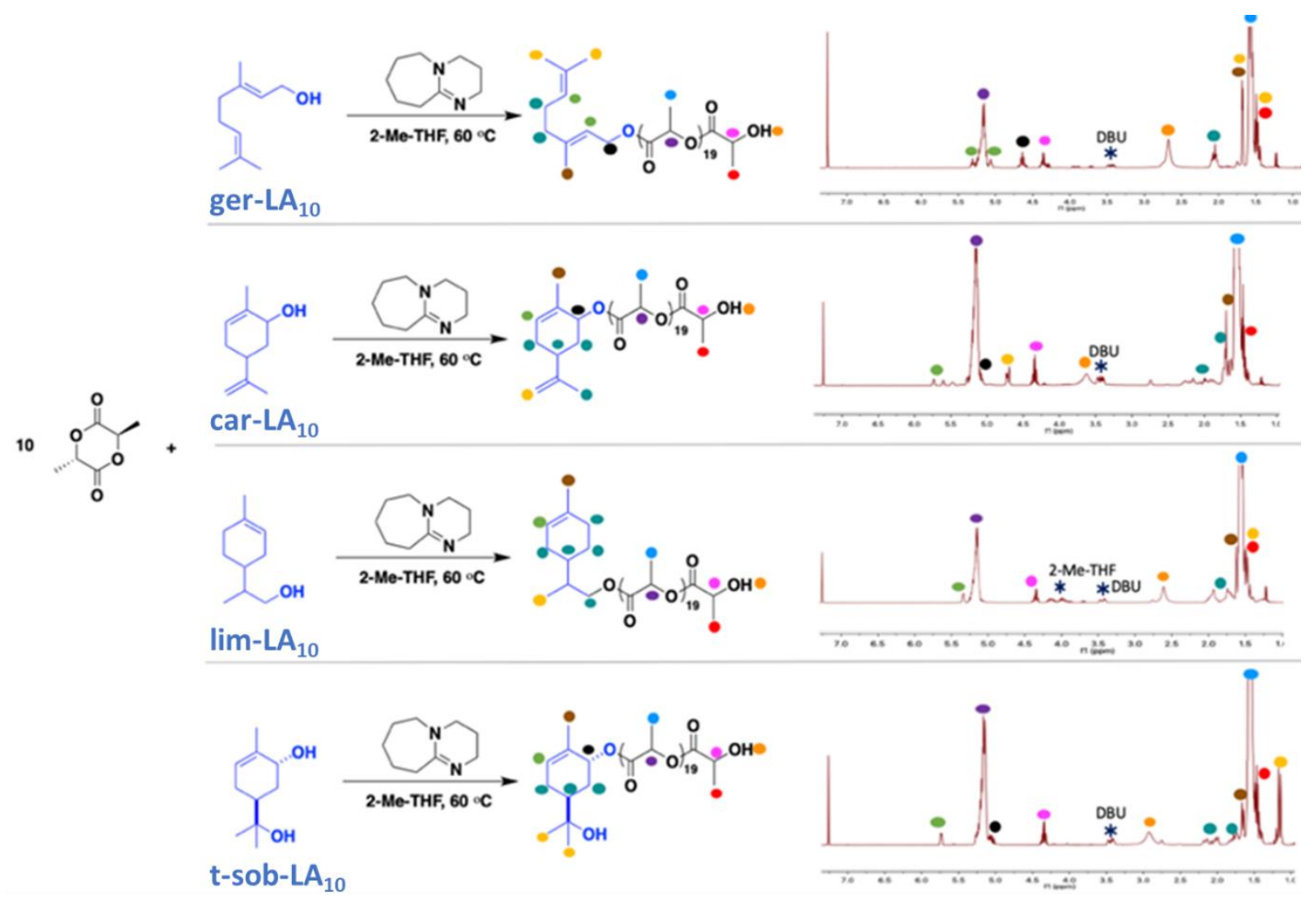

Figure S4. (Left) Reaction scheme of LA ROP with the four terpene initiators in 2-MeTHF. (Right) $1 \mathrm{H}-$ NMR of the final purified oligomers and main macromolecule peak assignments. 


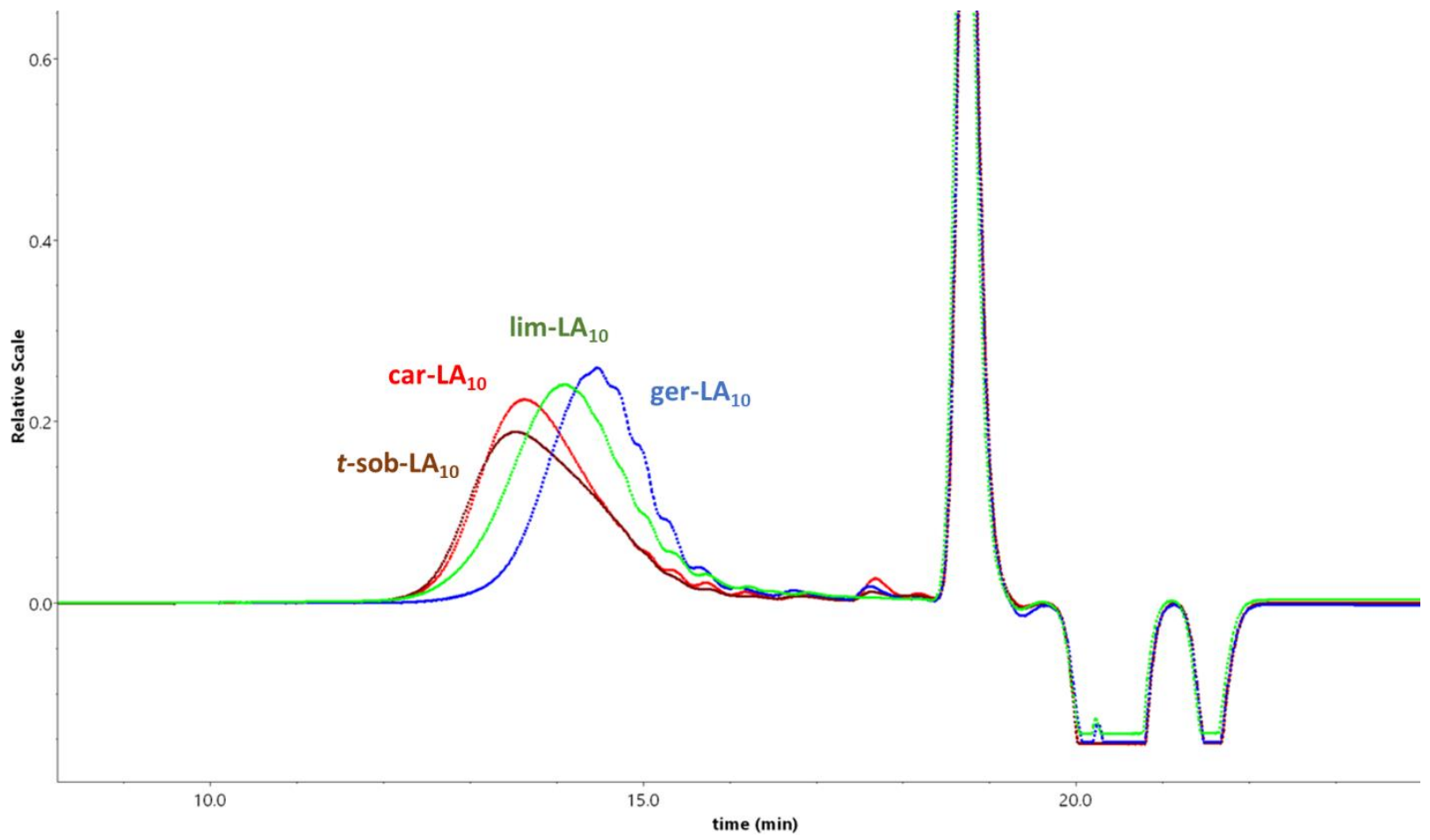

Figure S5. GPC RI traces vs retention time of the four oligomers, car- $\mathrm{LA}_{10}$, ger- $\mathrm{LA}_{10}, \lim -\mathrm{LA}_{10}$ and $t$-sob$\mathrm{LA}_{10}$ respectively. 


\section{lim-LA 10 stability in PBS}

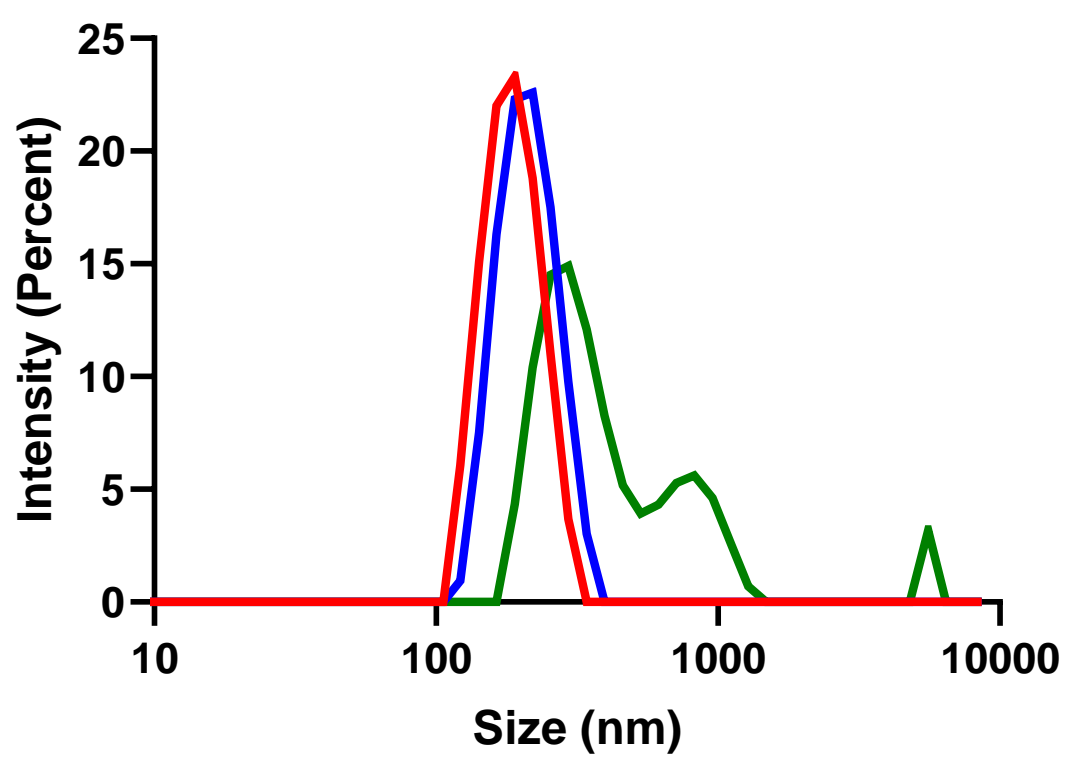

- t0_PBS

- t24h_PBS

- t48h_PBS

\section{t-Sob-LA 20 stability in PBS}

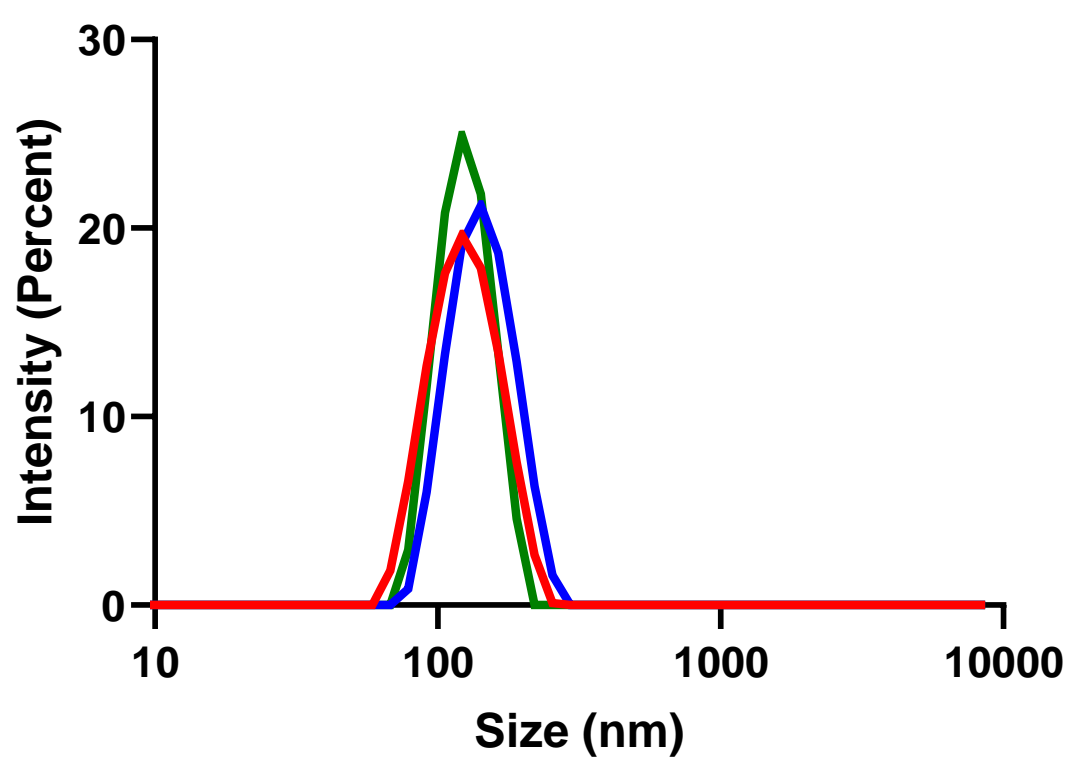

Figure S6. (Top) DLS traces of lim-LA 10 after dilution at $500 \mu \mathrm{g} / \mathrm{mL}$ with PBS at 0,24 and $48 \mathrm{~h}$. (Bottom) DLS traces of t-sob-LA 20 after dilution at $500 \mu \mathrm{g} / \mathrm{mL}$ with PBS at 0,24 and $48 \mathrm{~h}$. 